\title{
Desafios de uma nova gestão pública para o desenvolvimento dos municípios no Pará
}

\section{Challanges of a new public admmistration for the development of the munipalities of Para}

Josep Pont Vidal - Professor Associado do Núcleo Altos Estudos Amazônicos (NAEA), da Universidade Federal do Pará (UFPA). E-mail: vidalpont@yahoo.es

Duarte de Souza Rosa Filho - Professor do Departamento de Administração, da Universidade Federal do Espírito Santo (UFES). E-mail: duartes@gmail.com

\section{Resumo}

O desenvolvimento econômico em nível municipal tem sido tradicionalmente estudado a partir de variáveis econômicas, da estrutura política ou da capacidade endógena de inovar e criar riqueza. A hipótese teórica que guia esta pesquisa é que o desenvolvimento econômico de um município depende essencialmente da qualificação da gestão municipal. A partir de uma abordagem multidisciplinar e interdisciplinar, em nível metodológico, expõe-se a primeira fase da investigação, exploratória, baseada em uma metodologia quantitativa, em diversos municípios do estado do Pará. Expõem-se e analisam-se as variáveis planejamento e a gestão de pessoas. Como conclusão, observa-se a importância que adquire o planejamento a médio e longo prazos e a formação do pessoal para o fortalecimento institucional.

\section{Palavras-chave}

Gestão pública. Planejamento. Municípios. Instituições. Desenvolvimento. Estado do Pará.

\begin{abstract}
Economic development at the municipal level has traditionally been studied from economical, political structure, or the endogenous capacity to innovate and create wealth. The theoretical hypothesis guiding this research is that economic development in a municipality, mainly depends on the classification of municipal management. From a multidisciplinary and interdisciplinary, methodological level, it presents the first phase of research, essentially exploratory, based on a quantitative methodology in several counties of the state of Pará They expose themselves and analyze the variables: the planning and management people. In conclusion, we observe the importance of planning to acquire medium to long term and staff training for institutional strengthening.
\end{abstract}

\section{Keywords}

Plublic management. Planning. Municipalities. Institutions. Development. State of Pará. 


\section{INTRODUÇÃO}

Quando se estuda e se analisa o baixo desenvolvimento de algumas regiões, surgem questões centrais: quais são as variáveis estratégicas para alcançar o desenvolvimento'? Qual é a causa do baixo desenvolvimento? Na maioria dos estudos surgem variáveis de causa-efeito relacionadas com a economia e o desenvolvimento das forças produtivas (COSTA, 2005; 2006). O baixo desenvolvimento de um país ou de uma região é a consequência de um conjunto de fatores, como o nível educacional e contexto histórico, variáveis do sistema político (TEIXEIRA, 2002), a inovação, a economia de escala e o processo de acumulação capitalista. No entanto, como aponta Douglass North (1973), estes fatores não são as causas do baixo desenvolvimento, mas são consequência do próprio baixo desenvolvimento, ou seja, são resultados de uma baixa "organização eficiente". Como organizações eficientes, North coloca no centro do seu estudo a atividade humana. $\mathrm{O}$ autor se refere especificamente às instituições econômicas, $\mathrm{O}$ desenvolvimento "se traduz na própria visão do mercado como instituição e não como espaço neutro de encontro de compradores e vendedores" (ABRAMOVAY, 2001, p.167). Abramovay e North se referem concretamente às regiões e países de desenvolvimento baixo e médio (segundo definição do PNUD).

As instituições, entendidas como "produto e produtoras da ação humana" (BERGER; LUCKAMNN, 1995) adquirem, nesse sentido histórico, um papel determinante nos aspectos normativos referentes ao "cumprimento de contratos", mas também podem ser o resultado de uma forma de pensar e de planificar, e em consequência, de atuar e de agir. Abramovay indica que é basicamente o "ambiente social" o que inibe a inovação visto que este se apoia em "vínculos hierárquicos localizados e bloqueia a ampliação do círculo de relações sociais em que se movem as pessoas" (ABRAMOVAY, 2001, p. 168).

\footnotetext{
Neste trabalho, trata-se o conceito desenvolvimento, ao serem analisadas variáveis diretamente relacionadas com o desenvolvimento social e político dos municípios. É evidente que o desenvolvimento social só é possível quando vinculado ao desenvolvimento sustentável. Contudo, por razões de objetivo e delimitação da investigação, não se entra no debate de “desenvolvimento sustentável". Parte-se do conceito de desenvolvimento sustentável proposto pela Commision on Environment and Development, e a Brundtland Commission, em 1987: "O desenvolvimento econômico e social que satisfaz as necessidades da geração atual sem comprometer a capacidade das gerações futuras satisfazerem suas próprias necessidades".

Para mais informação, ver: XIMENES, T. (Org.). Perspectivas do desenvolvimento sustentável: uma contribuição para a Amazônia 21. Belém: NAEA, 1997; BECKER, D. F. (Org.). Desenvolvimento Sustentável. São Paulo: Edunisc, 1997. BRASIL. MINISTERIO DO MEIO AMBIENTE. Instrumentos econômicos para o desenvolvimento sustentável da Amazônia. Brasília, 2002; CAVAlCANTI, C. Meio Ambiente, Desenvolvimento Sustentável e Políticas Públicas. Recife: Fundação Joaquim Nabuco, 1997.
} 
Tentativas baseadas nas instituições e na correspondente gestão pública como variável explicativa independente de outros fenômenos sociais como o desenvolvimento econômico e social, salvo poucas exceções (FARIAS FILHO, 2004; 2004), são escassos, destacando os estudos que estabelecem uma relação entre gestão pública e monitoramento das desigualdades (SILVA JUNIOR, 2007) e gestão pública e desenvolvimento (NETO, 1995).

Quando nos referimos à Amazônia Oriental, devemos pensar que não se trata de uma região subdesenvolvida, mas de uma região de baixo desenvolvimento (segundo IDH, PIB per capita, e coeficiente Gini). A gestão municipal adquire um papel determinante para o desenvolvimento do município e, em consequência, da região, ao implicar a gestão financeira, de capital e infraestrutura, de pessoas e de tecnologias da informação, tendo como eixos transversais a capacidade de planejamento e os resultados. Seguindo esta lógica, a existência de modelos de gestão municipal que não se baseiam em um planejamento racional, na gestão orientada a resultados e na eficiência, e na formação dos recursos humanos disponíveis, constitui um obstáculo para o desenvolvimento econômico.

A hipótese que guia esta investigação é a seguinte: o fortalecimento institucional, e com ele a legitimidade e efetividade das propostas políticas de um município, depende essencialmente de uma serie de fatores internos da administração, especificamente da qualificação da gestão municipal em dois aspectos: 1) a capacidade de planejamento; 2) o modelo de gestão implementado. Este fato foi identificado por Abrucio e Pó (2002), ao analisar os temas centrais das reformas dos anos 90 e seus mecanismos institucionais, que identificam, entre outras, como "capacidade de gestão" as seguintes variáveis: 1) Capacitação de recursos humanos; 2) Criação de estruturas de carreiras e salários; 3) Avaliação e onitoramento de gestão

Nos municípios paraenses ainda predomina um modelo de gestão burocrático, sendo o modelo gerencial uma exceção (FARIAS FILHO, 2003). Por outro lado, o planejamento se limita frequentemente à resolução de problemas imediatos. Como consequência destes dois aspectos, predomina uma gestão "débil" que se manifesta em um baixo empoderamento da sociedade e uma dependência de fatores exógenos para o desenvolvimento. Neste texto, descrevemse os resultados parciais relativos, à investigação "Fortalecimento Institucional e Qualificação da Gestão Municipal"', referentes ao estudo das prefeituras do Estado do Pará. Expõem-se os dois fundamentos teórico-conceituais no que se baseia a investigação: o institucionalismo e a gestão pública.

\footnotetext{
Investigação financiada pelo Instituto de Pesquisas Econômica Aplicada (IPEA) e o Instituto de Desenvolvimento Socioeconômico do Pará (IDESP), realizadas entre 2009 e 2010.
} 


\section{REFERENCIAL TEÓRICO: INSTITUIÇÕES E MODELO DE GESTÃO PÚBLICA}

O fortalecimento institucional depende da capacidade de gestão das instituições, neste caso das prefeituras. O papel das instituições em impulsionar as mudanças, tem sido interpretado desde diferentes perspectivas, de tal forma que alguns autores, desde uma leitura interacionista, fundamentada na ação consciente dos homens, afirmam que estas "são produto e produtores das instituições" (BERGER; LUCKMANN, 1966, 1965), enquanto que outros se mostram céticos sobre a capacidade de mudança, pois estas podem "inibir" as reformas ao criar expectativas não satisfeitas pelas instituições (CAIDEN, 1999).

Uma contribuição para o papel das instituições para o desenvolvimento econômico, ou constitui a corrente neoinstitucionalista (MARCH; OLSEN, 1984; ANDREWS, 2005, entre outros). Não se trata de uma escola monolítica, Hall e Taylor (1996) diferenciam pelo menos três escolas de pensamento: o institucionalismo histórico, o institucionalismo da escolha racional e o institucionalismo sociológico (NORTH, 1995).

A obra do North constitui uma tentativa de sintetizar as contribuições teóricas procedentes da ciência política, da sociologia e da economia, é o denominado enfoque institucional. No esboço de uma teoria para a mudança social, North pretende explicar de que forma o passado influi no presente a partir da compreensão do desempenho das questões econômicas, nas quais as instituições têm um papel decisivo: "As instituições são as regras do jogo em uma sociedade". De forma similar à interpretação interaccionista - “as instituições são produto e produzidas pela atividade humana" - para compreender sua função não deve desconsiderar sua formação social: "são as limitações ideadas pelo homem que dão forma à interação humana”. Para isso, indica a necessidade de estudá-las em seu contexto histórico, visto que: "estruturam incentivos no intercâmbio humano, seja político, social ou econômico". Compreendê-las como produto social e histórico, significa lhes outorgar um papel determinante para a mudança social: "a mudança institucional conforma o modo em que as sociedades evoluem com o passar do tempo, é a chave para entender a mudança histórica...”. A mudança institucional "afeta a escolha estabelecida em certo momento e a natureza da dependência".

O estudo dos municípios do Pará trata de ampliar as concepções limitadas de compreensão da racionalidade em termos de uma racionalidade abstrata de fins e meios, abrindo uma reflexão as esferas influenciadas pelas práticas ligadas à

3 NORTH D. C. Instituciones, cambio institucional y desempeño econômico. México: Fondo de Cultura Económica / Economía Contemporánea, 1995. p. 13. 
cultura. Vários estudos sociológicos inspirados por Max Weber têm considerado as estruturas burocráticas dominantes nas sociedades contemporâneas como um produto de estruturas cada vez mais eficazes. No entanto, essa percepção se esquece de que as próprias práticas destas estruturas deveriam ser consideradas em seu tempo como práticas culturais. Essas práticas seriam paulatinamente incorporadas nas organizações e instituições, não somente no aspecto de aumentar a eficácia, mas também como consequência do processo de transmissão que dão origem às práticas culturais em geral.

O marco analítico do Novo Institucionalismo que trata de explicar o processo de tomada de decisões por parte dos atores políticos, tem como pressuposto básico a ideia de que a configuração das instituições afeta o comportamento dos atores sociais. Alguns autores (HALL; TAYLOR, 1996; PEREIRA PRATES, 2000) apontam a existência de, ao menos, três enfoques: o institucionalismo histórico, o da eleição racional e o sociológico, o também referido como teoria das organizações ${ }^{4}$. Nas correntes normativas, acentuam-se o papel dos atores políticos e das instituições como formadores de bons cidadãos. Na corrente histórica, acentua-se o papel de decisões históricas, as quais têm influência no desenvolvimento das instituições. Finalmente, a corrente sociológica resulta de uma síntese das anteriores, embora questione o determinismo histórico, dando ênfase nas influências do contexto social. A síntese da perspectiva sociológica e a histórica (DOBBIN, 1994). A perspectiva histórica é fundamental para a compreensão sobre o funcionamento das instituições e as agências governamentais e a ação estratégica dos atores frente e dentro delas, posto que estas sejam também produto da ação dos atores. A região da Amazônia Oriental (estado do Pará), como região em desenvolvimento, é uma região onde a presença do Estado manifesta-se com instituições distanciadas e fora dos problemas cotidianos da população, pela construção de algumas infraestruturas, que não têm contribuído para criar uma cidadania, sendo que esta, frente a projetos inacabados, tem estado historicamente excluída de tais processos, favorecendo a emergência de atores econômicos que tem orientado sua ação, enchendo o vazio e a "ausência" deixada pelo Estado e as instituições governamentais, aspectos já identificados por diversos autores (PINTO, 1980; COSTA, 1992; BRITO, 1998), de tal forma que se tem constituído uma "frágil institucionalidade" (TORRES, 2004) e nos aspectos relacionados com a gestão pública de "frágil tradição de controle" (REZENDE, 2002, p. 119).

O pensamento burocrático em que se fundamenta a gestão pública enfatiza os princípios básicos de uma forma administrativa tradicional descrita por Max Weber. Este modelo hierárquico burocrático se apoia no controle da esfera política

PETERS, 2003, considera a existência de pelo menos sete enfoques diferentes. 
sobre a esfera administrativa. O modelo está vertebrado em torno das estruturas burocráticas hierarquizadas, organizado a partir de superiores e subordinados. $\mathrm{O}$ procedimento correto e burocrático-administrativo prepondera na consecução de objetivos. Este fato comporta que os fluxos de informação e de autoridade sejam descendentes.

Este tipo de modelo burocrático está fortemente determinado pelo controle político da administração, sendo a esfera administrativa exclusivamente dependente da esfera política. Este fato produz uma dinâmica perversa. Por um lado, os políticos assumem competências de direção política das áreas e departamentos, intervindo, desta forma, na gestão diária da organização; por outro lado, os altos funcionários intervêm em numerosas ocasiões na tomada de decisões de caráter político. É importante mencionar que a divisão existente entre a administração e a política "não pode ser desprezada na determinação das responsabilidades de um e de outro grupo" (PARRADO DIEZ, 1996). Os planos de carreira estão pouco estruturados e a ascensão obedece geralmente ao princípio de antigüidade, e o tempo de serviço é o que normalmente determina as remunerações, sendo descartado o tipo de trabalho realizado ou a capacidade de trabalho dos funcionários.

A gestão também está imersa no esquema da falta de objetivos. Os orçamentos são elaborados em função de transferências e funções estatais e federais, desconsiderando-se outros tipos de programas. Por último, a estrutura organizativa segmentada em departamentos e secretarias estanques - e frequentemente concorrentes entre si - não ajuda a estabelecer uma visão ampla e integrada dos orçamentos. Trata-se, a partir de práticas incrementalistas, ou seja, apoiadas no cálculo de orçamentos e despesas do ano anterior, desconsiderando um planejamento orientado a objetivos. A política continuísta não possibilita a existência de canais que elevem as demandas e inquietações da cidadania às decisões superiores.

Com relação ao modelo gerencial, a meta da administração pública já não é simplesmente o cumprimento da lei - sem incorrer na ilegalidade - mas a introdução de maior rapidez nos serviços prestados pelos gestores, além de incluir melhorias. Cabe destacar que estas melhorias são tomadas unilateralmente, sem a consulta prévia aos usuários. 
Quadro 1. Critérios utilizados na pesquisa.

\begin{tabular}{|c|c|}
\hline COMPONENTE & $\begin{array}{l}\text { CRITÉRIOS DE UMA GESTÃO DÉBIL COM RELAÇÃO AO } \\
\text { PLANEJAMENTO }\end{array}$ \\
\hline Planejamento & Capacidade para estabelecer metas a médio e longo prazo \\
\hline $\begin{array}{l}\text { Instrumentos de } \\
\text { planejamento }\end{array}$ & $\begin{array}{l}\text { Planejamento fundamentado em indicadores, estudos socioeconômicos } \\
\text { o prognósticos }\end{array}$ \\
\hline $\begin{array}{l}\text { Planejamento de } \\
\text { concursos }\end{array}$ & Concursos para servidores previstos nos próximos anos \\
\hline $\begin{array}{l}\text { Capacitação de } \\
\text { funcionários }\end{array}$ & Intensidade e duração dos cursos de formação e reciclagem internos \\
\hline Tipo de gestão & Gestão orientada a resultados \\
\hline $\begin{array}{l}\text { Transparência da } \\
\text { gestão }\end{array}$ & Empoderamentos da sociedade e participação da sociedade civil \\
\hline Informação & $\begin{array}{l}\text { Disponibilidade da informação referente aos acordos da do plenário } \\
\text { municipal }\end{array}$ \\
\hline Planos municipais & Seguimento e utilização dos planos municipais: PD, PPA, PE, PDLS, PG. \\
\hline Acesso à informação & $\begin{array}{l}\text { Estrutura da arquitetura computacional } \\
\text { Acesso dos funcionários a sistemas de informática }\end{array}$ \\
\hline $\begin{array}{l}\text { Definição de } \\
\text { prioridades }\end{array}$ & $\begin{array}{l}\text { Instrumentos utilizados: estádios técnicos, secretarias, participação } \\
\text { entidades sociais }\end{array}$ \\
\hline $\begin{array}{l}\text { Planejamento } \\
\text { econômico }\end{array}$ & $\begin{array}{l}\text { Existência de mecanismo de controle } \\
\text { Existência de mecanismos de correção em caso de déficit público }\end{array}$ \\
\hline $\begin{array}{l}\text { Anos de atualização } \\
\text { de cadastros }\end{array}$ & Cadastros: IPTU, ISSQN \\
\hline $\begin{array}{l}\text { Planejamento na } \\
\text { criação de novas vagas }\end{array}$ & $\begin{array}{l}\text { Informações em que se baseia a criação de novas vagas: parâmetros de } \\
\text { políticas setoriais; demandas dos secretários; cadastro e movimentações } \\
\text { dos servidores. }\end{array}$ \\
\hline
\end{tabular}

Fonte: Elaboração dos autores.

\section{A ADMINISTRAÇÃO PÚBLICA NO ESTADO DO PARÁ}

A investigação inscreve-se na área de conhecimento da administração pública, e especificamente na gestão pública municipal. As prefeituras aparecem em muitos casos como o "nível pobre" nos diferentes níveis do Estado e da Administração Pública. Contudo, a realidade é algo diferente. Entre os anos 2000 e 2008, a maioria das prefeituras paraenses multiplicaram por cinco, o volume de receita orçamentária, como, por exemplo, Castanhal, que passou de mais de $\mathrm{R} \$ 25$ milhões (2000) a $\mathrm{R} \$ 130$ milhões (2008) ou Marabá, de $\mathrm{R} \$ 60$ (2000) a $\mathrm{R} \$ 315$ (2008). Este aumento tem sido significativo entre os anos 2005 e 2008, com recursos provenientes de uma parte importante do governo federal. Também o número de funcionários tem aumentado significativamente em todo o país, com uma média que 
ultrapassa os $30 \%$. Este aumento tem possibilitado o êxito de programas governamentais dirigidos diretamente pelas prefeituras, como o Programa Bolsa Família.

Tabela 1. Evolução da Receita Orçamentária de alguns municípios (2005-2008).

\begin{tabular}{l|r|r|r|r}
\hline Município & $\mathbf{2 0 0 5}$ & $\mathbf{2 0 0 6}$ & $\mathbf{2 0 0 7}$ & $\mathbf{2 0 0 8}$ \\
\hline Barcarena & $102.216 .72,27$ & $117.418 .834,9$ & $131.086 .825,9$ & $160.687 .681,7$ \\
\hline Castanhal & 88.877 .927 & $93.972,121$ & $108.314,437$ & $130.563,154$ \\
\hline Marabá & $155.502 .908,59$ & $165.596 .099,7$ & $200.937 .854,9$ & $315.743 .203,8$ \\
\hline
\end{tabular}

Fonte: Elaboração do autor, a partir de dados do SIE/IDESP.

Este fato é agravado pela dificuldade de tratá-lo no contexto da região amazônica, especificamente na Amazônia Oriental (estado do Pará), pois praticamente não existem estudos baseados em dados empíricos sobre a gestão pública, destacando-se poucos exemplos recentes, como o estudo de administração municipal (MONTEIRO, 1997), mudanças na administração pública (SOARES, CONCEIÇÃO, FARIAS FILHO, 2004) ou o programa do governo para modernizar a administração pública "Programa Qualidade na Gestão Pública no Estado do Pará" (2007). Como os estudos e trabalhos tratam-se, em geral, de monografias de caráter exploratório e baseados no método de estudo de caso, não é possível estabelecer conclusões que permitam generalizar.

Seguindo as recomendações de organismos internacionais e latinoamericanos (CLAD, documento: A New Public Management for Latin America, 1998), vários estudos e relatórios diagnosticaram uma "crise da administração pública burocrática" e a necessidade de "empreender" reformas (LONGO; YSA, 2008, p.17). Esta crise não se manifesta somente nos aspectos técnicos e científicos, mas também pela própria complexidade destes novos cenários, tanto locais quanto globais, que se configuram nas agendas públicas e nas próprias falhas do sistema de mercado hegemônico e propostas neoliberais de "retrocesso" ou de "diminuição do Estado". Todos se traduzem na necessidade de produção de respostas por parte das administrações públicas, diante dessa nova realidade. Os cenários político-institucionais são apontados como determinantes na superação dos marcos estáveis para superar a crise. Para fornecer respostas, objetiva-se que cada vez mais as intervenções públicas devem ser realizadas com a colaboração das diversas instâncias e com diferentes autoridades hierarquizadas das administrações, isto é, com a colaboração de atores de diferentes hierarquias da mesma organização ou por organizações fora do sistema público. 
O Brasil não se encontra isento deste processo, e, apesar dos importantes avanços no último quarto de século, em toda a administração pública, a Confederação Nacional de Municípios (CNM) publicou em 2008 a coletânea Gestão 2009-2012. A Nova Administração Pública, em que se justifica: "Transformações tecnológicas, estruturais, econômicas e sociais exercem grandes impactos na vida das pessoas, sendo que estes impactos consequentemente refletem nas gestões por elas lideradas" (CNM, 2008, p.8). Com esta proposta, aborda-se um "Modelo de administração pública voltado para a eficiência, eficácia e efetividade" (Ibid., p.14). No documento básico surgem os conceitos e as diretrizes principais, tais como "Gestão Baseada em Processos" (Ibid., p.33), "condução para a eficiência", "excelência" e "Orientação para o público “(ibid., p.15-17), também trata aspectos constituintes como a tecnologia de gestão e o planejamento estratégico.

Diversos autores (LANDER, 1998; BRESSER-PEREIRA; CUNILL GRAU, 1998; BRESSER-PEREIRA, 2004) sugerem a necessidade de estabelecer uma governança dos sistemas públicos contemporâneos. As organizações sociais, denominadas por Bresser-Pereira (2004) “público não estatal”, demandam cada vez mais da exigência na prestação de serviços públicos. Nos últimos anos, o mercado e as redes, disputam, cada vez mais, no poder público, um papel protagonista predominante na prestação de serviços, especialmente na saúde e em outros campos sociais. Confrontar a governança (governabilidade) na gestão pública significa adotar uma série de critérios que deverão orientar os procedimentos administrativos e a gestão (DENTE,1995; DE LIMA, 2001).

Diversos autores diagnosticaram a emergência de um "Estado Relacional" incipiente, compreensível talvez no contexto das democracias da Europa Ocidental, mas não para a região amazônica. Esta região, que faz parte da "periferia da periferia" (MELLO, 2007), e que por sua capacidade de desenvolvimento institucional pode ser caracterizada como região de "baixa institucionalidade" (TORRES, 2004). A realidade de muitos municípios paraenses se expressa claramente no estudo de Monteiro (1997, p. 153):

[...] A forma como se administra o município, no caso de realidade paraense, continua presa à tradição patrimonialista. Os gestores municipais utilizaram os cargos públicos "como uma extensão de seus negócios particulares e de seus familiares” (MONTEIRO, 1997, p. 153).

\section{MODELO DE ANÁLISE}

A análise do sistema de administração do Estado que se tem analisado, é interpretado como um processo de retroalimentação sistêmica contínuo temporal, em que o processo de retroalimentação se sucede a partir de quatro fases: 
planejamento, monitoramento, avaliação e controle. Analisa-se, a partir de quatro grandes subsistemas, os quais englobam o núcleo de funções comuns de todos os níveis do governo: 1) Gestão financeira; 2) Gestão de capital e infraestrutura; 3) Gestão de pessoas; 4) Gestão de tecnologia da Informação (Figura 1).

O planejamento, no subsistema da gestão financeira, compreende questões como a realização de estudos socioeconômicos, os mecanismos de acompanhamento e controle, e mecanismos de correção em caso de déficit municipal. No subsistema da gestão de capital e infraestrutura, compreende questões relativas a: os instrumentos utilizados para definir as prioridades dos investimentos, e os instrumentos de subsídio no planejamento. A avaliação e controle da gestão de pessoas compreendem os instrumentos de atendimento e comunicação ao cidadão, tais como o balcão integrado de atendimento ou a existência da ouvidoria pública, entre outros itens.

Quanto aos subsistemas, a qualificação da Gestão financeira municipal representa a mais usual setorização da gestão municipal, e que influencia de maneira decisiva o modelo de gestão a ser implementado. O departamento financeiro normalmente é o primeiro setor a se estabelecer, tendo acesso direto ao prefeito pelo seu envolvimento a tomada de decisões relacionada a orçamento e despesas do município. Ainda conforme o autor, a área financeira é a que mais detém regulamentações legais e é a pioneira na implementação de novas tecnologias, investindo principalmente em sistemas mais integrados.

\section{A Gestão de pessoas (GP) é um componente essencial de qualquer}

sistema de gestão. É implementada para garantir a utilização do capital humano de forma eficaz e eficiente, para que sejam alcançadas as metas do governo. A GP refere-se às políticas, sistemas e práticas que influenciam comportamentos, atitudes e desempenho de funcionários e, consequentemente, o desempenho da instituição. As atividades operacionais de práticas de gestão de pessoas são vastas, incluindo estratégia de planejamento da força de trabalho, recrutamento de funcionários potenciais, seleção de trabalhadores, formação e desenvolvimento de funcionários, gerenciamento de mérito e reconhecimento de funcionários, avaliação de desempenho do funcionário, classificação de posições, criação de um ambiente de trabalho positivo e saudável (relações interpessoais) e administração de recompensas aos empregados. 
Quadro 2. Conceitos e critérios utilizados na pesquisa.

\begin{tabular}{|c|c|c|c|}
\hline CONCEITO & CRITÉRIOS & INDICADOR & CÁLCULO \\
\hline \multirow[t]{6}{*}{$\begin{array}{l}\text { Gestão } \\
\text { financeira }\end{array}$} & $\begin{array}{l}\text { Perspectivas e Planeja- } \\
\text { mento Orçamentário }\end{array}$ & $\begin{array}{l}\text { Relação do cálculo do } \\
\text { ano fiscal com a vota- } \\
\text { ção do orçamento }\end{array}$ & Ano fiscal: data \\
\hline & & $\begin{array}{l}\text { Nível de dependência } \\
\text { Estadual e federal }\end{array}$ & Participação \% \\
\hline & & Leis orgânicas vigentes & Definição das leis \\
\hline & $\begin{array}{l}\text { Saúde e estabilidade } \\
\text { fiscal }\end{array}$ & Gestão da divida & Médio e longo prazo \\
\hline & $\begin{array}{l}\text { Parcerias Público- } \\
\text {-privadas }\end{array}$ & $\begin{array}{l}\text { Parcerias: estado-fede- } \\
\text { ral-empresas privadas }\end{array}$ & $\begin{array}{l}\text { Cálculo em } \% \text { do total } \\
\text { do orçamento }\end{array}$ \\
\hline & Planejamento e execução & $\begin{array}{l}\text { Estudos socioeconô- } \\
\text { micos }\end{array}$ & $\begin{array}{l}\text { Estudos realizados se- } \\
\text { gundo estrato }\end{array}$ \\
\hline \multirow[t]{4}{*}{$\begin{array}{l}\text { Gestão de } \\
\text { capital e } \\
\text { infraestrutura }\end{array}$} & $\begin{array}{l}\text { Planejamento e orça- } \\
\text { mento de capital }\end{array}$ & $\begin{array}{l}\text { Implementação siste- } \\
\text { ma padronizado com } \\
\text { registro }\end{array}$ & $\begin{array}{l}\text { Horizonte deste planeja- } \\
\text { mento (anos) }\end{array}$ \\
\hline & $\begin{array}{l}\text { Subsídios do } \\
\text { planejamento }\end{array}$ & $\begin{array}{l}\text { PD, PPA, PE, PS, PG, } \\
\text { PDLS, }\end{array}$ & $\begin{array}{l}\text { Utilização e implemen- } \\
\text { tação dos Planos }\end{array}$ \\
\hline & Participação da poplação & $\begin{array}{l}\text { Conselhos, Orçamento } \\
\text { Participativo, Audiên- } \\
\text { cias públicas }\end{array}$ & Regularidade \\
\hline & $\begin{array}{l}\text { Manutenção de bens e } \\
\text { infraestrutura }\end{array}$ & $\begin{array}{l}\text { Bens móveis, demais } \\
\text { bens, bens de uso pú- } \\
\text { blico }\end{array}$ & $\begin{array}{l}\text { Periódica, Preventiva, } \\
\text { Reparadora }\end{array}$ \\
\hline \multirow[t]{5}{*}{$\begin{array}{l}\text { Gestão de } \\
\text { pessoas }\end{array}$} & $\begin{array}{l}\text { Análise estratégica ne- } \\
\text { cessidades de GP }\end{array}$ & $\begin{array}{l}\text { Geração de resultados } \\
\text { de acordo com objeti- } \\
\text { vos e metas }\end{array}$ & Metas e objetivos \\
\hline & $\begin{array}{l}\text { Obtenção de funcioná- } \\
\text { rios qualificados }\end{array}$ & $\begin{array}{l}\text { Realização de concurso } \\
\text { público }\end{array}$ & $\begin{array}{l}\text { Contratação de funcio- } \\
\text { nários efetivos } \\
\text { Contratação de funcio- } \\
\text { nários temporários }\end{array}$ \\
\hline & $\begin{array}{l}\text { Retroalimentação dos } \\
\text { funcionários }\end{array}$ & $\begin{array}{l}\text { Programas de treina- } \\
\text { mento }\end{array}$ & $\begin{array}{l}\text { Realização de cursos de } \\
\text { capacitação }\end{array}$ \\
\hline & Treinamento & $\begin{array}{l}\text { Programa de treina- } \\
\text { mento }\end{array}$ & $\begin{array}{l}\text { Frequência do Programa } \\
\text { de treinamento }\end{array}$ \\
\hline & Engajamento do cidadão & $\begin{array}{l}\text { Participação na elabo- } \\
\text { ração dos Planos }\end{array}$ & Instrumentos utilizados \\
\hline
\end{tabular}

Fonte: Elaboração dos autores.

\section{PROCEDIMENTOS METODOLÓGICOS}

No estado do Pará foram selecionados 29 municípios, sobre um total de 144, com os que conta o estado, representando 20,1\%. Estes foram selecionados de forma aleatória, a partir de variáveis. A razão pela qual foi escolhida uma 
mostra aleatória estratificada e não uma amostra aleatória simples baseia-se em três critérios: primeiro, a estratificação pode produzir um erro; segundo, o custo da observação; terceiro, a estimação dos parâmetros populacionais e desejáveis para os subgrupos da população. A forma de especificar os estratos é um problema mais difícil do que aparenta, em um primeiro momento. Na investigação, decidiuse pelo critério de número de habitantes e do PIB per capita.

Parte-se da premissa de que a variável do PIB per capita é um indicador importante, visto que os municípios com diferentes PIB têm capacidade de gestão diferenciada. Quanto à importância da variável população, deve-se ao seu critério básico para o volume de transferências de recursos econômicos governamentais aos municípios, como a faixa de população municipal (FPM). A estratificação dos municípios foi dividida segundo 8 estratos. Os municípios selecionados correspondem também a cada uma das 11 "Regiões de integração" (Quadro 3).

A aplicação dos questionários se realizou entre os secretários dos respectivos municípios, com visitas personalizadas, sendo possível o retorno das respostas alguns dias mais tarde, em face da complexidade e extensão das questões a responder de maneira exata. ${ }^{5} \mathrm{O}$ índice de questionários respondidos, foi, no entanto, baixo.

Quadro 3. Critérios técnicos de seleção de municípios.

\begin{tabular}{|c|c|c|c|c|}
\hline \multirow{2}{*}{$\begin{array}{c}\text { Faixas de } \\
\text { população }\end{array}$} & \multicolumn{4}{|c|}{ PIB per capita do Estado } \\
\hline & \multicolumn{2}{|c|}{ Abaixo } & \multicolumn{2}{|l|}{ Acima } \\
\hline $\begin{array}{l}\text { Até } 20.000 \\
\text { habitantes }\end{array}$ & $\begin{array}{l}\text { Total municípios }= \\
43,00 \\
\text { Desvio-Padrão PIB } \\
\text { per capita = 1032,16 } \\
\text { Média PIB per capita } \\
=2835,34 \\
\text { Peso estrato = } 0,13 \\
\text { Tamanho da amostra } \\
=3,64 \\
\text { Tamanho da amostra } \\
\text { final }=4,00\end{array}$ & $\begin{array}{l}\text { Terra Alta } \\
\text { Placas } \\
\text { Piçarra } \\
\text { Senador José } \\
\text { Porfírio }\end{array}$ & $\begin{array}{l}\text { Total municípios }=6,00 \\
\text { Desvio-Padrão PIB per } \\
\text { capita }=2825,37 \\
\text { Média PIB per capita } \\
=10201,02 \\
\text { Peso estrato }=0,05 \\
\text { Tamanho da amostra } \\
=1,39 \\
\text { Tamanho da amostra } \\
\text { final }=1,00\end{array}$ & Anapu \\
\hline
\end{tabular}

5 A investigação de campo foi realizada durante os meses de março a junho de 2010. Foram formulados quatro tipos de questionários: Bloco A: Gestão financeira; Bloco B: Gestão de capital e infraestrutura; Bloco C: Gestão de pessoas; Bloco D: Gestão de Tecnologia da Informação. Cada um deles está composto entre 11 e 23 perguntas. 


\begin{tabular}{|c|c|c|c|c|}
\hline $\begin{array}{l}\text { Entre } 20.000 \\
\text { e } 100.000 \\
\text { habitantes }\end{array}$ & $\begin{array}{l}\text { Total municípios }= \\
72,00 \\
\text { Desvio-Padrão PIB } \\
\text { per capita = 934,57 } \\
\text { Média PIB per capita } \\
=2940,04 \\
\text { Peso estrato = } 0,19 \\
\text { Tamanho da amostra } \\
=5,52 \\
\text { Tamanho da amostra } \\
\text { final }=5,00\end{array}$ & $\begin{array}{l}\text { Altamira } \\
\text { Anajás } \\
\text { Aurora do } \\
\text { Pará } \\
\text { Vigia } \\
\text { São } \\
\text { Domingos } \\
\text { do Araguaia }\end{array}$ & $\begin{array}{l}\text { Total municípios } \\
=12,00 \\
\text { Desvio-Padrão PIB per } \\
\text { capita }=15790,50 \\
\text { Média PIB per capita } \\
=16564,51 \\
\text { Peso estrato }=0,54 \\
\text { Tamanho da amostra } \\
=15,53 \\
\text { Tamanho da amostra } \\
\text { final }=15,00\end{array}$ & $\begin{array}{l}\text { Almeirim } \\
\text { Água Azul } \\
\text { do Norte } \\
\text { Tucuruí } \\
\text { Canaã dos } \\
\text { Carajás } \\
\text { Benevides } \\
\text { Tucumã } \\
\text { Oriximiná } \\
\text { Barcarena } \\
\text { Paragominas } \\
\text { São Félix do } \\
\text { Xingu } \\
\text { Redenção } \\
\text { Xinguara }\end{array}$ \\
\hline $\begin{array}{l}\text { Entre } 100.000 \\
\text { e } 500.000 \\
\text { habitantes }\end{array}$ & $\begin{array}{l}\text { Total municípios }= \\
7,00 \\
\text { Desvio-Padrão PIB } \\
\text { per capita }=1410,47 \\
\text { Média PIB per capita } \\
=3871,14 \\
\text { Peso estrato = } 0,03 \\
\text { Tamanho da amostra } \\
=0,81 \\
\text { Tamanho da amostra } \\
\text { final }=1,00\end{array}$ & Bragança & $\begin{array}{l}\text { Total municípios }=2,00 \\
\text { Desvio-Padrão PIB per } \\
\text { capita }=12915,38 \\
\text { Média PIB per capita } \\
=22187,30 \\
\text { Peso estrato }=0,07 \\
\text { Tamanho da amostra } \\
=2,12 \\
\text { Tamanho da amostra } \\
\text { final }=2,0\end{array}$ & $\begin{array}{l}\text { Parauapebas } \\
\text { Marabá }\end{array}$ \\
\hline $\begin{array}{l}\text { Acima de } \\
500.000 \\
\text { habitantes }\end{array}$ & $\mathrm{NE}$ & & $\begin{array}{l}\text { Total municípios }=1,00 \\
\text { Desvio-Padrão PIB per } \\
\text { capita }= \\
\text { Média PIB per capita } \\
=8765,47 \\
\text { Peso estrato }=0,00 \\
\text { Tamanho da amostra } \\
=0,00 \\
\text { Tamanho da amostra } \\
\text { final }=1,00\end{array}$ & Belém \\
\hline
\end{tabular}

Legenda: NE: Não Existem municípios nesse estrato.

Fonte: Pesquisa IPEA/IDESP.

Não menos importante nesse item sobre metodologia é o processo de trabalho multidisciplinar realizado. Trata-se de uma pesquisa realizada em dois níveis: Estadual e Federal. No primeiro nível, tratou-se de uma pesquisa baseada na multidisciplinaridade, visto que a finalidade de equipe de investigadores foi "resolver problemas" concretos da investigação (PIAGET, 1978), desde sua área de conhecimento, tais como, a construção teórica de conceitos, a partir de leituras específicas procedentes de diversas áreas do conhecimento e a formulação dos questionários, para posteriormente serem aplicados. A interdisciplinaridade entre os investigadores foi o desafio que se tinha que superar no segundo nível da 
investigação - a comparação federal entre os diversos estados ${ }^{6}$. Trata-se de uma "interdisciplinaridade restringida" (BIOSOT, 1972), ou seja, focalizada em função do objeto concreto de investigação. Os trabalhos em equipe, as leituras e críticas das investigações mencionadas mostraram sua utilidade: aplicável - de forma crítica e mantendo as distâncias - em alguns aspectos da realidade dos municípios brasileiros. Ao final, estruturam-se dois subsistemas principais: 1) Gestão financeira; 2) Gestão de pessoas. A partir destes eixos, um segundo passo foi aprofundar sobre os conceitos utilizados e propor novos conceitos, a análise da visão sistêmica da gestão municipal e a pauta metodologia e técnica da investigação de campo.

\section{FORTALECIMENTO INSTITUCIONAL MUNICIPAL NO ESTADO DO PARÁ}

A configuração atual dos municípios paraenses e sua evolução histórica, desde 1988 é um tema já tratado por diversos autores (ROCHA, 2008), assim como os novos recortes municipais (SILVA, 2008). No estado do Pará, assim como em outros Estados da União são muitos os municípios que, para viabilizar as políticas setoriais, procuram recursos e dependem “diretamente dos repasses dos tributos do governo Estadual e da União, sem, contudo, apresentarem políticas que os tornem capazes de aumentar suas arrecadações, e assim dar soluções aos seus problemas urbanos e rurais" (SILVA, 2008, p.78). Este fenômeno se manifesta de forma especial nos municípios de recente criação. No estado do Pará, desde 1980 criaram-se mais de 60 novos municípios, passando de 83 em 1980 para os atuais $144 \mathrm{em} 2010$. Quanto ao estrato populacional mais importante, o constituem municípios entre 20.000 e 100.000 habitantes, somando, neste estrato, um total de 84 municípios. Com esses dados, evidencia-se que o número de habitantes desses municípios se converte em uma variável-chave para aumentar suas arrecadações, seja por impostos locais ou por transferências federais. Para gerenciar esta situação são necessárias duas condições: a capacidade de planejar, e de dispor de pessoal adequadamente qualificado.

Para medir a capacidade de planejamento na gestão financeira, têm-se construído diversos indicadores. A realização de estudos socioeconômicos, como elemento básico para o planejamento, todavia, é mínima nas prefeituras de tamanho médio, e maior nas menores. No entanto, este dado não esclarece o tipo de estudos, a metodologia utilizada e a aplicação e seguimento por parte dos gestores municipais. Especialmente as prefeituras médias têm poucos mecanismos

6 Estados de Alagoas, Rio de Janeiro, Paraná, Pernambuco e Espírito Santo. 
de acompanhamento e controle a curto e longo prazos, assim como de atualização do Imposto Sobre a Propriedade Territorial Urbana (IPTU) e do Imposto Sobre Serviço Qualquer Natureza (ISSQN). Estes aspectos podem ter como consequência que, em caso de endividamento, vejam-se obrigados a tomar medidas drásticas, como o aumento da arrecadação de impostos e do endividamento. Um salto qualitativo se manifesta nas prefeituras grandes, as quais se baseiam em estudos prévios para planejamento e acompanhamento a curto e longo prazos (Tabela 2).

Quanto à gestão de capital e infraestrutura, enquanto a prefeitura grande utiliza vários tipos de estudos - técnicos, participação de entidades - também as decisões do prefeito, nos municípios médios e pequenos se adotam outras estratégias. Nas prefeituras pequenas, aparece a participação das entidades sociais como o instrumento para definir as prioridades dos investimentos, sendo mais importantes que as decisões do prefeito e os estudos técnicos. A situação varia nas prefeituras médias, nas quais aparece um equilíbrio entre estudos técnicos, decisões do prefeito e participação das entidades.

Como instrumentos de subsídio ao planejamento de investimentos, nas prefeituras pequenas existem o Plano Plurianual, o Plano de Governo e o Plano Diretor como os mais importantes. Nas prefeituras médias, apesar da obrigação de dispor do Plano Diretor, este não é utilizado em 85 \% delas, enquanto que o PPA é o instrumento mais utilizado. Na prefeitura grande, são o Plano Plurianual, o Plano Estratégico e o Plano de Governo. O Plano de Desenvolvimento Local Sustentável (PDLS) surge como um instrumento pouco utilizado em todos os tipos de prefeituras (Tabela 3).

O precário planejamento ou o planejamento insuficiente tem consequências na gestão de pessoas, especificamente na previsão de concurso para os próximos anos. Menos da metade das prefeituras médias têm previsto a realização de concursos. Este fato pode ser resultado da falta de informações para a criação de novas vagas, embora esta ausência se manifeste de diferente forma, segundo o estrato de prefeitura que se trata. Evidencia-se, nas prefeituras pequenas, como as que mais importância dão aos parâmetros das políticas setoriais, embora a prefeitura de grande porte obedeça às demandas das Secretarias. A existência de planos de cargos (PCS e PCCR) constitui um problema para as prefeituras pequenas e médias. Por último, um problema de primeira ordem no que constitui a falta de encontrar profissionais dispostos a trabalhar e viver nas prefeituras médias e pequenas do interior do Pará (Tabela 4). 

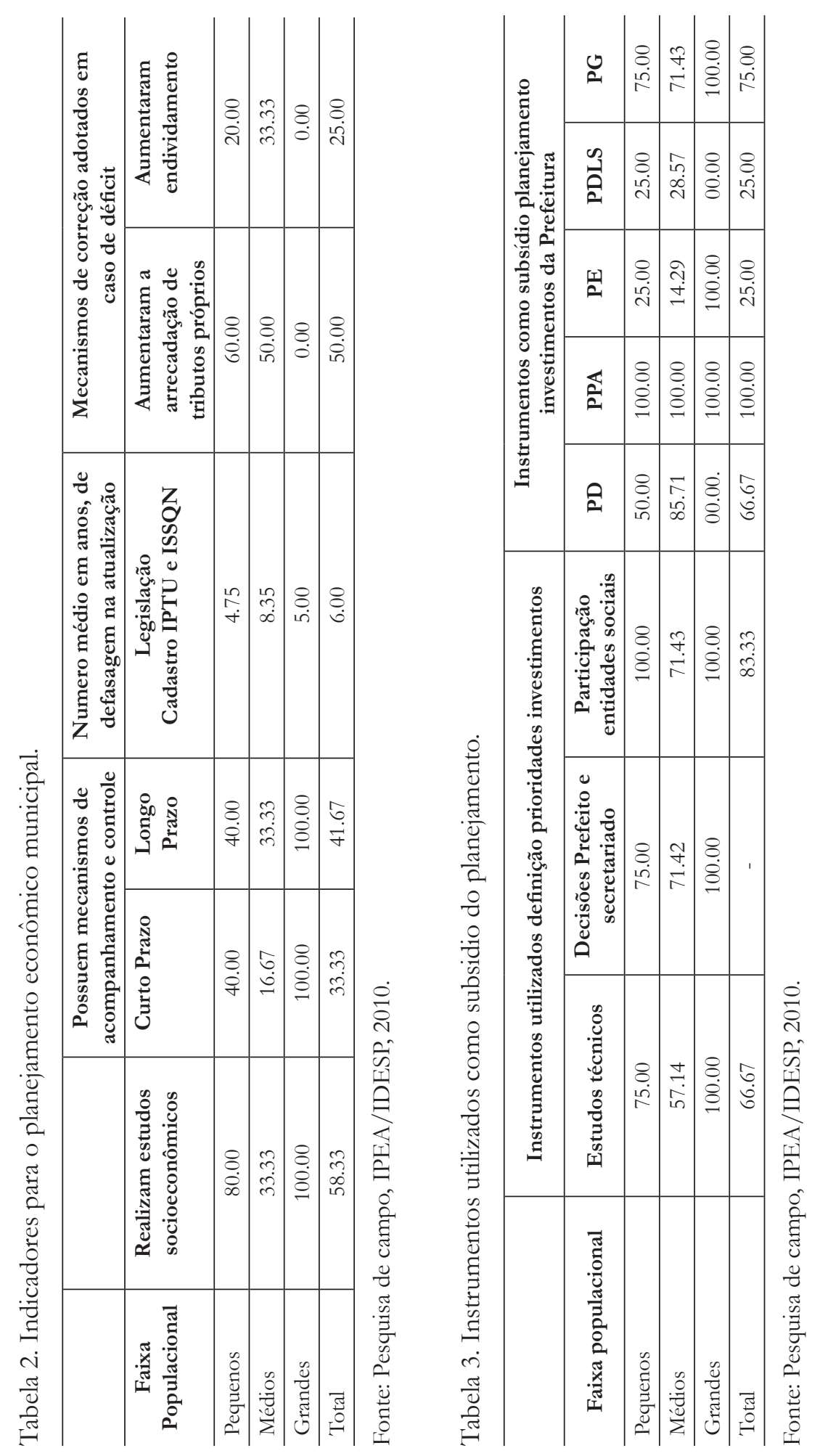


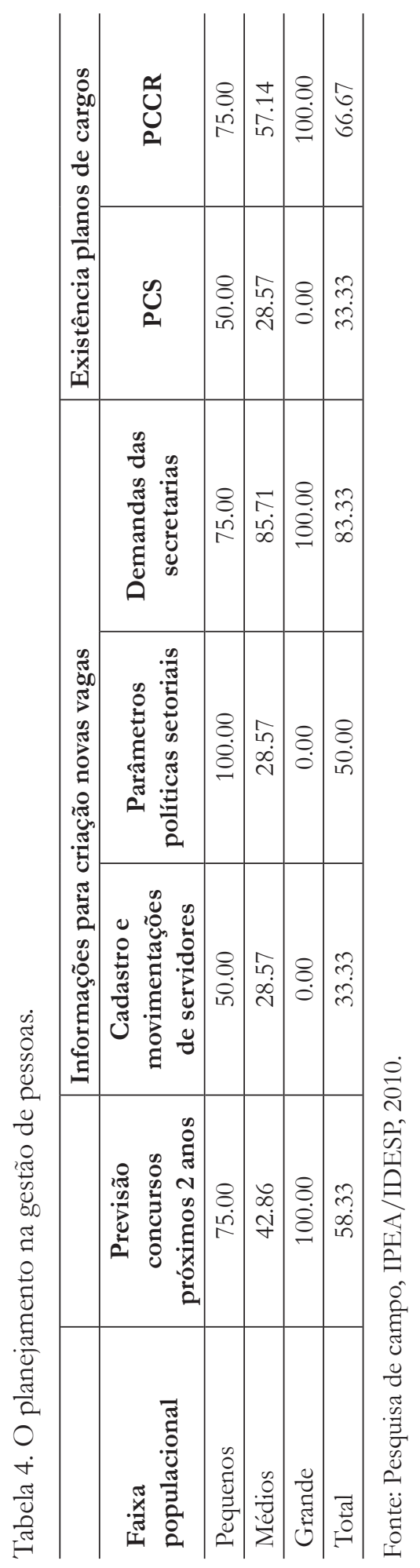


Possivelmente o problema do precário planejamento é uma consequência da deficiente capacitação do pessoal da prefeitura. Todavia, realizam-se poucos cursos de capacitação, com poucas horas dedicadas. Este fato surge alarmante na gestão de tecnologia da informação. Dispor de um moderno sistema de hardware ou de software em uma prefeitura não significa necessariamente uma maior eficácia e eficiência, dado que muitos funcionários dispõem apenas de conhecimentos básicos de informática (Tabela 5).

Tabela 5. Nível de capacitação dos funcionários das prefeituras.

\begin{tabular}{|c|c|c|c|c|}
\hline \multirow{3}{*}{$\begin{array}{c} \\
\text { Faixa } \\
\text { populacional }\end{array}$} & \multicolumn{3}{|c|}{ Gestão pessoas } & \multirow{3}{*}{$\begin{array}{c}\text { Gestão } \\
\text { tecnologia } \\
\text { Informação } \\
\text { Capacitação } \\
\text { de pessoas }\end{array}$} \\
\hline & \multirow{2}{*}{$\begin{array}{c}\text { Cursos } \\
\text { capacitação } \\
\text { funcionários } \\
\text { Prefeitura }\end{array}$} & \multicolumn{2}{|c|}{$\begin{array}{c}\text { Realização de curso } \\
\text { de capacitação }\end{array}$} & \\
\hline & & $\begin{array}{c}\text { Programação } \\
\text { de cursos \% }\end{array}$ & $\begin{array}{c}\text { Demandas } \\
\text { especificas \% }\end{array}$ & \\
\hline Pequenos & 75.00 & 50.00 & 50.00 & 25.00 \\
\hline Médios & 71.43 & 57.14 & 57.14. & 28.57 \\
\hline Grandes & 100.00 & 100.00 & 100.00 & 25.00 \\
\hline Total & 75.00 & 58.33 & 58.33 & 33.33 \\
\hline
\end{tabular}

Fonte: Pesquisa de campo, IPEA/IDESP, 2010.

Quanto à gestão - financeira, de capital, de pessoas -, nos municípios médios não é possível estabelecer uma tendência clara. Nesta área, aparecem contradições como: é possível a existência de uma equipe responsável para o planejamento dos investimentos sem dispor previamente de estudos socioeconômicos? Aparentemente é diferente a situação nos municípios pequenos, nos que afirmam realizar estudos socioeconômicos, ter uma equipe responsável pelo planejamento e realizar previsão de concurso nos próximos dois anos. Contudo, na amostra empírica não se especifica a tipologia, profundidade e qualidade dos estudos socioeconômicos, assim como tampouco a composição da equipe responsável do planejamento (Tabela 6). 
Tabela 6. O planejamento da gestão em diferentes áreas.

\begin{tabular}{l|c|c|c}
\hline & Gestão financeira & $\begin{array}{c}\text { Gestão de capital } \\
\text { e infraestrutura }\end{array}$ & Gestão de pessoas \\
\hline $\begin{array}{l}\text { Faixa } \\
\text { populacional }\end{array}$ & $\begin{array}{c}\text { Realizam estudos } \\
\text { socioeconômicos }\end{array}$ & $\begin{array}{c}\text { Possui equipe responsável } \\
\text { pelo planejamento dos } \\
\text { investimentos }\end{array}$ & $\begin{array}{c}\text { Previsão de } \\
\text { concurso próximos } \\
2 \text { anos }\end{array}$ \\
\hline Pequenos & 80.00 & 75.00 & 75.00 \\
\hline Médios & 33.33 & 85.71 & 42.86 \\
\hline Grandes & 100.00 & 100.00 & 100.00 \\
\hline Total & 58.33 & 83.33 & 58.33 \\
\hline
\end{tabular}

Fonte: Pesquisa de campo, IPEA/IDESP, 2010.

\section{FORTALECIMENTO INSTITUCIONAL E DESENVOLVIMENTO}

A gestão pública na região da Amazônia Oriental não pode se limitar a apenas uma boa "gestão", no sentido amplo da expressão, mas deve ser também orientada ao desenvolvimento. Para isso deve se cumprir uma série de exigências e desafios.

O desenvolvimento econômico produz "como consequência da utilização do potencial e do excedente gerado localmente e a atração, eventualmente, de recursos externos" (VAZQUEZ-BARQUERO, 2000; 2001), assim como outros autores que tomam a variável econômica e institucional como variável independente (NORTH, 1981; WILLIAMSON, 1985). O desenvolvimento econômico produz, como consequência, quatro determinantes entrelaçados, que podem favorecer ou dificultar o desenvolvimento: 1) a difusão das inovações do conhecimento; 2) a organização flexível da produção; 3) o desenvolvimento urbano do território; 4) a densidade do tecido institucional (VAZQUEZ-BARQUERO, 2001). Nestes quatro elementos aparecem de forma transversal, com maior ou menor intensidade, o papel dos atores locais, concretamente, as decisões tomadas por eles e o papel das instituições. As instituições como portadoras e transmissores de uma cultura e em consequência de uma forma de organização, podem favorecer os processos de desenvolvimento.

Com as falhas detectadas nas políticas públicas no nível macro, devido entre outros aspectos, à sua homogeneidade e falta de adaptação, o município adquire um papel estratégico na formulação e execução de políticas públicas para o desenvolvimento. Existe um conjunto de explicações sobre o fenômeno da falta de planejamento - o "planejamento fraco", a médio e longo prazo, pode explicar segundo o foco, o nível de abstração e a forma como se argumenta. 
Quatro elementos aparecem como determinantes na composição de uma gestão pública municipal por resultados: 1) o contexto institucional; 2) as falhas sequenciais da gestão; 3) a arquitetura organizacional; 4) a cultura de planejamento. Figura 2. Interligação dos quatro níveis que compõem a gestão pública municipal.

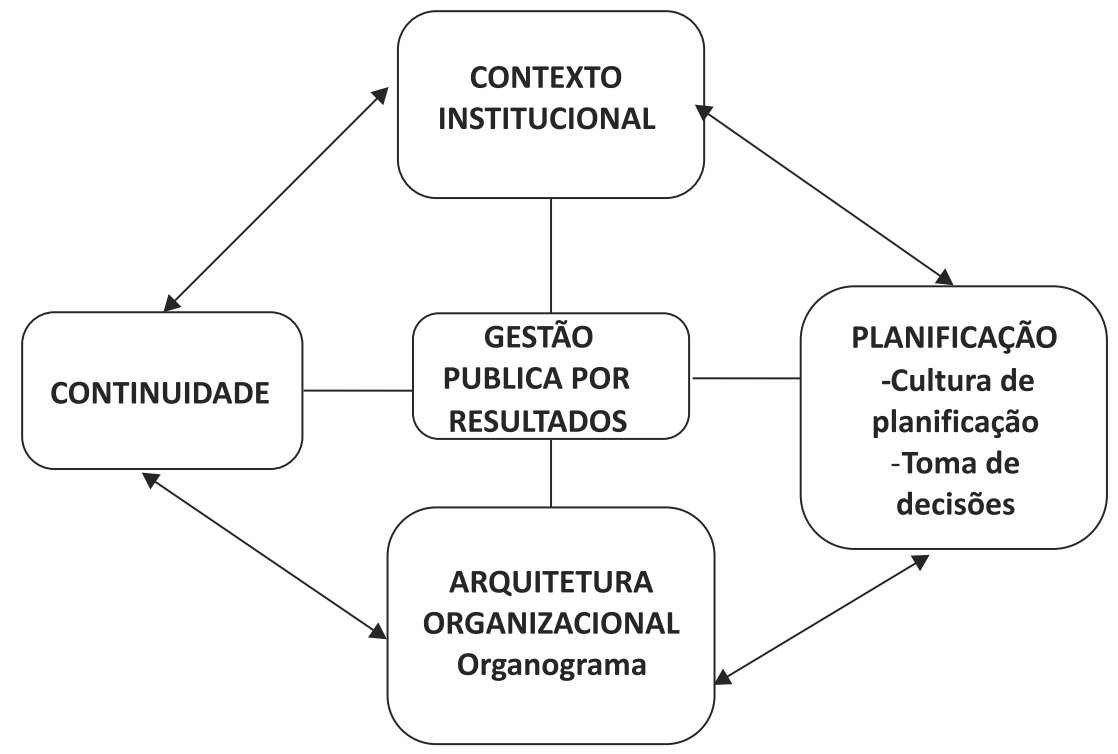

Fonte: Elaboração dos autores.

O contexto institucional faz parte dos estudos das diversas vertentes do institucionalismo, o qual incorpora em sua análise elementos estruturais do governo e seus elementos históricos e normativos. Refere-se à institucionalidade existente na própria prefeitura, como em outras instituições municipais, estaduais e federais, com as quais a prefeitura possui vínculos. A Teoria da Delegação (MELO, 1996) se refere à responsabilização dos governantes no controle da agenda pública e das agências estatais. A continuidade e as "falhas sequenciais" constituem um elemento de análise essencial para compreender os mecanismos geradores destas falhas nas reformas gerenciais. As continuidades-descontinuidades da gestão "descontinuidades, abandonadas, terminadas" (REZENDE, 2004, p.34), não foram estudadas na investigação, embora possam entrever como uma atitude que prejudica enormemente o desenvolvimento. Não é uma exceção observar em prefeituras projetos iniciados obras públicas anunciadas por um prefeito, e abandonadas no momento em que aparece uma mudança de representantes no poder político municipal. Entre as hipóteses que se estabelecem, as reformas falham essencialmente a partir de mecanismos causais como: os custos de transação envolvidos nas reformas, os legados de desempenho ou o dilema do controle (REZENDE, 2004). 
A arquitetura organizacional ou o organograma municipal constitui um elemento determinante, que pode reduzir o grau de efetividade da gestão, visto que obedece em alguns casos as decisões arbitrárias e, portanto, sem um conceito racional. A arquitetura organizacional influi também na gestão de projetos estratégicos, como diversos estudos apontam (CURY, 2007; MAXIMIANO, 2007; MARIANI, 2008), e, finalmente, acrescenta-se a cultura do planejamento (HOFSTEDE, 1999; REZENDE, 2004).

A gestão pública não só deve dar resposta às exigências e demandas atuais, mas também deve ser orientada ao desenvolvimento do município e da região. Embora a gestão pública municipal não incida diretamente sobre o desenvolvimento socioeconômico do município, consideramos necessário que a gestão pública induza uma série de práticas de mudança da cultura e do nível operativo, com o objetivo de fortalecer e acelerar a modernização da instituição pública:

- Otimização dos recursos públicos. As prefeituras recebem recursos a partir de diversos programas federais, além de outras fontes próprias ou através de parcerias com empresas privadas. Uma eficiente gestão destes recursos e o estabelecimento de prioridades de investimentos é um elemento básico para o fortalecimento institucional.

- Introdução de uma cultura de postos e responsabilidades. Esta cultura se baseia na meritocracia e na competência dos servidores públicos. Contratação de pessoal preparado e competente para desempenhar as funções é básico para que a administração possa oferecer serviços de qualidade ao cidadão. Esta nova cultura da meritocracia há de enterrar práticas de caráter endogâmico e nepótico, comuns em muitos municípios.

- Internalizando uma cultura de planejamento. A construção de um futuro com melhor qualidade de vida para os habitantes, e para evitar situações de improvisação nos planos de carreira e na criação de novas vagas e concursos, dependem da introdução de uma cultura de planejamento em todas as secretarias e níveis municipais. Colocar em prática o Plano Diretor seria um avanço neste sentido.

- Introduạir uma cultura de formação e reciclagem constante dos funcionários. A formação dos funcionários, para otimizar o hardware e o software, é indispensável para o bom funcionamento dos serviços da prefeitura. Dado o baixo índice de formação dos funcionários em algumas prefeituras, a oferta de cursos de formação homologados e de estágios temporais de funcionários em outras prefeituras selecionadas como "casos de boa gestão municipal" são elementos que favoreceriam a introdução de novas práticas de gestão.

- Otimização do organograma municipal. Estruturado de forma mais funcional e racional, orientado a resultados e as novas demandas da cidadania e da sociedade e não orientado ao poder público.

Finalmente, estas dimensões podem sintetizar-se na cultura do planejamento. 


\section{CONCLUSÕES}

Cada sociedade possui formas específicas de organização das instituições e a cultura e as formas de organização, as quais facilitam ou dificultam o desenvolvimento econômico. A organização destas instituições está fortemente condicionada por uma cultura. Nas prefeituras pequenas e médias paraenses detecta-se a falta de normalização de uma cultura de planejamento financeiro e de mecanismos e acompanhamento e controle na área da gestão financeira, que nos municípios pequenos e grandes, tem efeitos negativos. Surpreendentemente, em todas as prefeituras se destina pessoal para estas tarefas. A falta de cultura de planejamento tem como consequência, no caso de déficit orçamentário - como é na maioria das prefeituras do Pará - que tenham que tomar medidas drásticas de redução de despesas e de procura de transferências voluntárias, seja de origem federal ou estadual. Entretanto, aparece a questão: as prefeituras pequenas e médias possuem pessoal suficientemente capacitado e qualificado para procurar linhas orçamentárias e realizar os correspondentes trâmites de formulação e gestão de projetos e ações governamentais?

A ação da prefeitura e a gestão para o desenvolvimento, por menores que sejam, não se restringem aos limites do município, mas, isto reflete, em maior ou menor medida, um contexto institucional e de ação política mais ampla em nível estadual. Não surpreendentemente, no mundo da física se tem visto a conclusão: o infinitamente pequeno, e o infinitamente grande, guardam os mesmos segredos.

\section{REFERÊNCIAS}

ABRAMOVAY, R. Desenvolvimento e instituições: a importância da explicação histórica". In: ARBIX, G.; ZILBOCIUS, M.; ABRAMOVAY, R. Razões e fricções do desenvolvimento. São Paulo: UNESP, 2001, p.165-177.

ABRUCIO, F. L.; PÓ, M. V. Trajetórias da literatura sobre reforma do Estado (1995-2002): transformações e desafios para a pesquisa em administração pública. Brasília: ENAP, 2002. Relatório de Pesquisa.

ALDAY, H.; CONTRERAS, E. Planejamento Estratégico dentro do Conceito de Administração Estratégica. Revista FAE, Curitiba, v. 3, n. 2, mai/ago. 2000.

ANDREWS, C. W. Implicações teóricas do novo institucionalismo: uma abordagem habermasiana. Dados, v.48, n.2, p.271-299. Apr./June, 2005.

ARMSTRONG, A; ELVINS, R. The New Public Management. The way ahead? Disponível em: <http://www.users.bigpond.com/elvins.cons/Evaluation \%20 of $\% 20$ NPM.pdf $>$ Acesso em: 20 jun. 2009. 
AZEVEDO, S.; MELO, M. A. Mudanças institucionais, reforma da seguridade social e reforma tributária. São Paulo: Ford; Anpocs, 1996. Relatório de Pesquisa. BERGER, P.; LUCKMANN, Th. A construção social da realidade. Tratado sobre a sociologia do conhecimento. Petrópolis: Vozes, [1966], 1995.

BRANDÃO, H. P.; GUIMARÃES, T. de A. Gestão de competências e gestão de desempenho: tecnologias distintas ou instrumentos de um mesmo construto? Revista de Administração de Empresas, São Paulo, v. 41, n. 1, jan/mar. 2001.

BRASIL. Constituição da República Federativa do Brasil de 1988. Disponível em: <http:/ /www.planalto.gov.br/ccivil_03/constituicao/ constitui\%C3\%A7ao. htm>. Acesso em: 3 ago. 2009.

BRESSER-PEREIRA, L. C. Macroeconomia da Estagnação. Cap. 10-11. São Paulo: Editora 34, 2007.

CAIDEN, G. "Administrative reform: proceed with caution",International Journal of Public Administration, v. 22, n. 6, p. 815-832, 1999.

COELHO, V. S.; NOBRE, M. Participação e Deliberação: teoria democrática e experiências institucionais no Brasil contemporâneo. São Paulo: Editora 34, 2004.

CONFEDERAÇÃO NACIONAL DE MUNICIPIOS. Nova Administração Pública: Gestão Municipal e Tendências Contemporâneas. Brasília, 2008.

CONSTANZA, R. Ecological Economics: The Science and Management of Sustentability. New York: Columbia University Press, 1991.

COSTA, F. de A. Arranjos e sistemas produtivos e inovativos locais. As possibilidades do conceito na constituição de um sistema de planejamento para a Amazônia. Revista Brasileira de Inovação, v. 5, n.1, jan./ jun. 2006.

COSTA, F. de A. Dossiê amazônia brasileira e questão agrária e macropolíticas para a Amazônia. Estudos Avançados, v.19, n. 53, jan./apr. 2005.

COSTA, F. An integrated research and development initiative towards sustainable management of family agriculture in Eastern Amazônia. In: Conference on International Agricultural Research for Development - Deutscher Tropentag, 2001. Bonn. Anais... Bonn, 2001.

DENTE, B. El proceso de reforma de la Administración en Italia. Gestión y Análisis de Políticas Públicas, n. 2. Enero-abril., 1995. Disponible em: <http:// www.scielo.cl/scielo.php?script $=$ sci_arttext\&pid=S0250-71612000007900003\&ln $\mathrm{g}=\mathrm{es} \& \mathrm{nrm}=\mathrm{iso}>$. Accedido em: 26 jul. 2010.

DOBBIN, F. Forging Industrial Policy. Cambridge: Cambridge University Press, 1994. 
DOGON, M. The Hydridization of Social Science Knowletge. Library Trends, v. 5, n. 2, p. 296-314, 1996.

DOWNS, A. Uma teoria econômica da democracia. São Paulo: Edusp, [1957], 1999.

ELSTER, J. Nuts and Bolts for the Social Sciences. Cambridge: Cambridge University Press, 1989.

FARIAS FILHO, M. C. Organizações e instituições: uma abordagem exploratória a partir de experiências de mudanças no setor público. Adcontar, v.5, n.1. p. 1534, jun. 2004.

FARIAS FILHO, M. C. Reforma administrativa e arranjos Institucionais: a experiência do Estado do Pará. 2003. Tese (Doutorado) - Núcleo de Altos Estudos Amazônicos/Universidade Federal do Pará, Belém, 2003.

GEERTZ, C. O saber local: novos ensaios em antropologia interpretativa. Tradução de Vera Mello Joscelyne. Petrópolis: Vozes, 1997. 366p.

GOWLER, D.; LEDGE, K. The Meaning of Management and the Management of Meaning: A view from Social Antropology. In: EARL, M. (Ed.). Perspectives in Management a Multidisciplinary Analysis. Oxford: Oxford University Press, [s.d.]. p. 197-234.

HABERMAS, J. Teoría de la acción comunicativa: complementos y estudios previos. Madrid: Cátedra, 2001.

HOFSTEDE, G. Culturas y organizaciones. Madrid: Alianza editorial, 1999.

IBGE. Programa de Melhora da Qualidade da Gestão Institucional: Aumentando a governança do IBGE. Disponível em: http://unstats.un.org/ unsd/statcom/statcom_09/seminars/innovation/Innovation \%20Seminar/Brazil_ Paper_UNSD_feb_2009\%20-\%20versao\%20final.pdf > Acesso em: 2 maio 2010.

LIMA, B. O. La Nueva Gestión Pública. Madrid: Pearson Educación, 2001.

MAAR, L. Cultura e globalização: uma apresentação crítica. In: OLIVEIRA, F. A. (Org.). Globalização, Regionalização e Nacionalismo. São Paulo, UNESP, 1998. p. 141-180.

MAIMON, D. Ensaios sobre Economia do Meio Ambiente. Rio de Janeiro: APED, 1992.

MARCH, J.; OLSEN, J. Neo-institucionalismo: fatores organizacionais na vida política”. Revista Sociologia Politica, v.16, n.31, p.121-142, nov. 2008. 
MARCH, J.; OLSEN, J. The New institutionalism: organizational factors in political life. American Political Science Review, n. 78, 1984.

MARIANI, E. J. A importância da arquitetura organizacional na gestão do setor público municipal: estudo de caso da secretaria municipal de administração (sma) da prefeitura municipal de Porto Alegre. 2008. Monografia (Especialização em Gestão Pública) - Instituto Brasileiro de Gestão de Negócios, Porto Alegre, 2008.

MARIANI, E. A importância da arquitetura organizacional na gestão do setor público municipal: estudo de caso da secretaria municipal de administração (sma) da prefeitura municipal de Porto Alegre. Porto Alegre: IBGEN, 2008.

MAXIMIANO, A.C. Introdução à Administração. São Paulo: Atlas, 2007.

McNICOL, S. The Interdisciplinary Research Landscape. Journal of Librarianship and Information Science, 35, n.1, p. 23-30, 2003.

MELO, M.A. Estado, governo e políticas públicas. In: MICELI, S. (Org.). O que ler na Ciência Social brasileira (1970-1995). Ciência Política. São Paulo: Sumaré; Brasília: Capes, 1999.

MONTEIRO, M. S. Nomeação e Concurso: máquina burocrática estatal e denominação política. 1997. Dissertação (Mestrado) - Núcleo de Altos Estudos Amazônicos/Universidade Federal do Pará, Belém, 1997.

MORILLO, F.; BORDONS, M.; GÓMEZ, I. Interdisiplinarity in Science: a Tentative Typology of Diciplines and Reseach Areas. Journal of the American Society for Information Science and technology, v. 54, n. 13, p. 1237-1249, 2003.

NETO, P.S. Gestão publica e desenvolvimento. Estudos Avançados, v. 9, n. 23, jan/april, 1995.

NORTH, D. C. Instituciones, cambio institucional y desempeño económico. [s.l.]: Fondo de Cultura Económica/Economía Contemporánea, 1995.

NORTH, D. C.; THOMAS, R. P. The Rise of the Western World: a new economic history. Cambridge: Cambridge University Press, 1973.

OLSON, M. The logic of Collective Action. Cambridge: Harvard University Press, 1965.

PARRADO DIEZ, S. La implantación de la 'Nueva Gestión Publica' en el 'viejo' continente: la experiencia anglosajona como modelo. In: CONGRESO ESPAÑOL DE C ${ }^{a}$ POLÍTICA Y DE LA ADMINISTRACIÓN. 1996 Santiago de Compostela. Annales... Santiago de Compostela, 1996. 
PEREIRA, J. M. Finanças Públicas: a política orçamentária no Brasil. 4. ed. São Paulo: Atlas, 2009.

PIAGET, J. La Equilibración de las estructuras cognitivas. Madrid: Siglo XXI, 1978.

REZENDE, F. da C.. Por que falham as Reformas Administrativas? Rio de Janeiro: FGV, 2004.

REZENDE, F. Razões da crise de implementação do estado regencial: desempenho versus ajuste fiscal. Revista Sociologia Política, n. 19, p.111-121, nov. 2002.

RICHARDS, S. Improving public management. London: Sage [1988], 1995.

SILVA JUNIOR, W. Gestão publica e monitoramento das desigualdades socioespaciais: o mapa da exclusão/inclusão social de Itajaí. Terr@Plural, v. 1, n. 1, 2007.

SILVER, B. J. Fuerzas de trabajo. Los movimientos obreros y la globalización desde 1870. Barcelona: Akal, 2005.

SIMON, H. A. Comportamento Administrativo. Rio de Janeiro: FGV, 1963.

SOARES, A.; CONCEIÇAO, J.; FARIA FILHO, M. As mudanças na Administração pública no contexto de reformas institucionais dos estados nacionais: a experiência do estado do Pará (1991-2002). Adcontar, v. 5, n.1, p. 15-34, 2004.

TEIXEIRA, E. C. O papel das políticas públicas no desenvolvimento Local e na transformação da realidade. Políticas Públicas. O papel das Políticas Públicas. 2002.

VAZQUEZ-BARQUERO, A.V. Desenvolvimento endógeno em tempos de globalização. Porto Alegre. Fundação de Economia e Estatística, 2001. 280 p.

VAZQUEZ-BARQUERO, A. Desarrollo endógeno y globalización. EURE (Santiago), v. 26, n. 79, dic. 2000.

VIDAL, J. Continuidade e mudança na gestão pública do estado do Pará. São Paulo: Paco, 2011.

VIEIRA, P.F.; MAIMON, D. (Orgs.). As Ciências sociais e a questão ambiental: rumo à interdisciplinaridade. Belém: APED/NAEA, 1993.

WILLIAMSON, O. The economic institutions of capitalism. New York: The Free Press, 1985. 